\title{
Mode Research on Selection of Curtain Wall Type Based on Analytic Hierarchy Process
}

\author{
Yihua Mao ${ }^{1, ~ a}$, Zhongyang $\mathrm{Xu}^{1, \mathrm{~b}^{*}}, \mathrm{Yi} \mathrm{Du}^{1, \mathrm{c}}$, Xin Chang ${ }^{1, \mathrm{~d}}$ and Jingping $\mathrm{Li}^{1, \mathrm{e}}$ \\ ${ }^{1}$ College of Civil Engineering and Architecture, Zhejiang University, Hangzhou, Zhejiang, China \\ amaoyihua@zju.edu.cn, b21412002@zju.edu.cn, cduyi@163.com d308695525@qq.com, \\ elijingping980322@163.com \\ *The corresponding author
}

Keywords: Analytic hierarchy process; Curtain wall; Method of type selection; Mode research

\begin{abstract}
The curtain wall type selection is one of the most important parts of curtain walls construction. To make a scientific selection of curtain wall, this paper extracts 15 factors which may impact curtain wall selection. Basing on this index system, we raise a curtain wall type selection model using Analytic Hierarchy Process (AHP).
\end{abstract}

\section{Instroduction}

The curtain wall type selection means to pick out the type of curtain wall which satisfies the requirement of function, schedule and quality, including materials and structure form. It's a typical multi-objective decision problem. By far, the selection of curtain wall mainly depends on designer's experience and preference or developer's requirement and preference leading to lack of systematic argumentation and comparison between different types of curtain wall. The theoretical research on curtain wall type selection is scarce. Only a minority of scholars at home and abroad do contrast research qualitatively on unit and frame curtain wall. To fill the gap, this paper sets a curtain wall type selection model based on Analytic Hierarchy Process (AHP) and do case study.

\section{The Extraction of Curtain Wall Type Selection Factors}

In order to select appropriate curtain wall type, we must extract the factors that impact the selection first. Our research extracts 16 factors through studying the main process of design, construction and management of curtain wall construction with Delphi technique.

(1) Design cost (DC), the cost happens in design period of curtain wall construction.

(2) Airborne sound insulation performance (ASIP), curtain wall is supposed to cut off the noise from outside and the curtain wall itself must absorb sound.

(3) Water tightness performance (WTP), the basic capability of curtain wall that prevents permeation

(4)Air tightness performance (ATP), the curtain wall should resist the air infiltration while meets the requirement of wind pressure.

(5) Resistance to wind load performance (RTWLP), curtain wall should maintain normal and cannot occur any damage when curtain wall meets wind load (in the vertical direction).

(6) Plane deformation performance (PDP), all the structure of curtain wall should keep the Stability of structure property when displacement occurs to.

(7) Thermal performance (TP), under the condition of differential temperature, curtain wall should cut off energy transfer to a certain degree.

(8) Optical performance (OP), the curtain wall which must meet the requirement or lighting should let enough light permeate through curtain wall.

(9) Crashworthiness performance (CP), curtain wall should work under certain impulse force.

(10) Quality assurance (QA), different type of curtain wall differs from site condition and construction method leading to diverse construction quality.

(11) Construction period (COP), the construction period length varies from construction method 
of curtain construction.

(12) Construction cost (CC), the cost occurs in the construction stage.

(13) Maintaining performance (MP), different types of curtain wall have different cost and difficulties while maintaining.

(14) Safety performance (SP), in construction stage and operate stage, the safety performance of curtain wall varies from the type.

(15) Applicability performance (AP), diverse curtain wall adapt to diverse construction and structure requirements.

\section{Method of Curtain Wall Selection with AHP}

Analytic Hierarchy Process (AHP) is one of the classical methods to solve the problem of multi-objective decision whose fundamental principle is decomposing the complex problems that are waited to identify into several hierarchies. Then experts and decision makers compare the importance of the indexes in pairs giving scores one by one. They take advantage of eigenvector of the identification matrix to determine the contributions from lower hierarchy index to upper hierarchy index. And then get the arrangement of the importance of fundamental indexes to the total target, namely the weight vector.

The study of curtain wall type selection with AHP is organized as follows.

(1) Establish hierarchical structure model. Target layer: the goal of this decision is to select an appropriate plan of a curtain wall project. Criterion layer: includes PS, CC, DC, ASIP, WTP, RTWLP, PDP, TP, OP, CP, QA, MP, COP, AP. The importance degree of the 13 indexes are diverse. Plan layer: includes curtain wall plan 1, curtain wall plan 2, curtain wall plan 3 and so on. Each plan shows different superiority on the four indexes mentioned above. The hierarchical structure model we establish shows in Fig. 1.

(2) Structure comparison matrix in pairs. The comparison matrix table of criterion layer shows in Table 1, plan layer in Table 2. We let experts evaluate with one-nine method of AHP in both criterion layer and plan layer.

(3) Sort with single criterion and make consistency check. With the results of comparison matrix, we get the sort of weight of criterion layer element relative to target layer relative to and plan layer element relative criterion layer element. Meanwhile acquire the result of consistency check.

(4) Get the weight of hierarchy general sorting and make consistency check. Through the calculation of weight vector, we obtain the sort of weight of plan layer relative to target. And make consistency check.

(5) Decision. The final weight vector we get represents the virtues and defect degree of different curtain wall plans. The higher the weight is, the better it is to solve the problem. Thus the decision should tend to make according to it. 


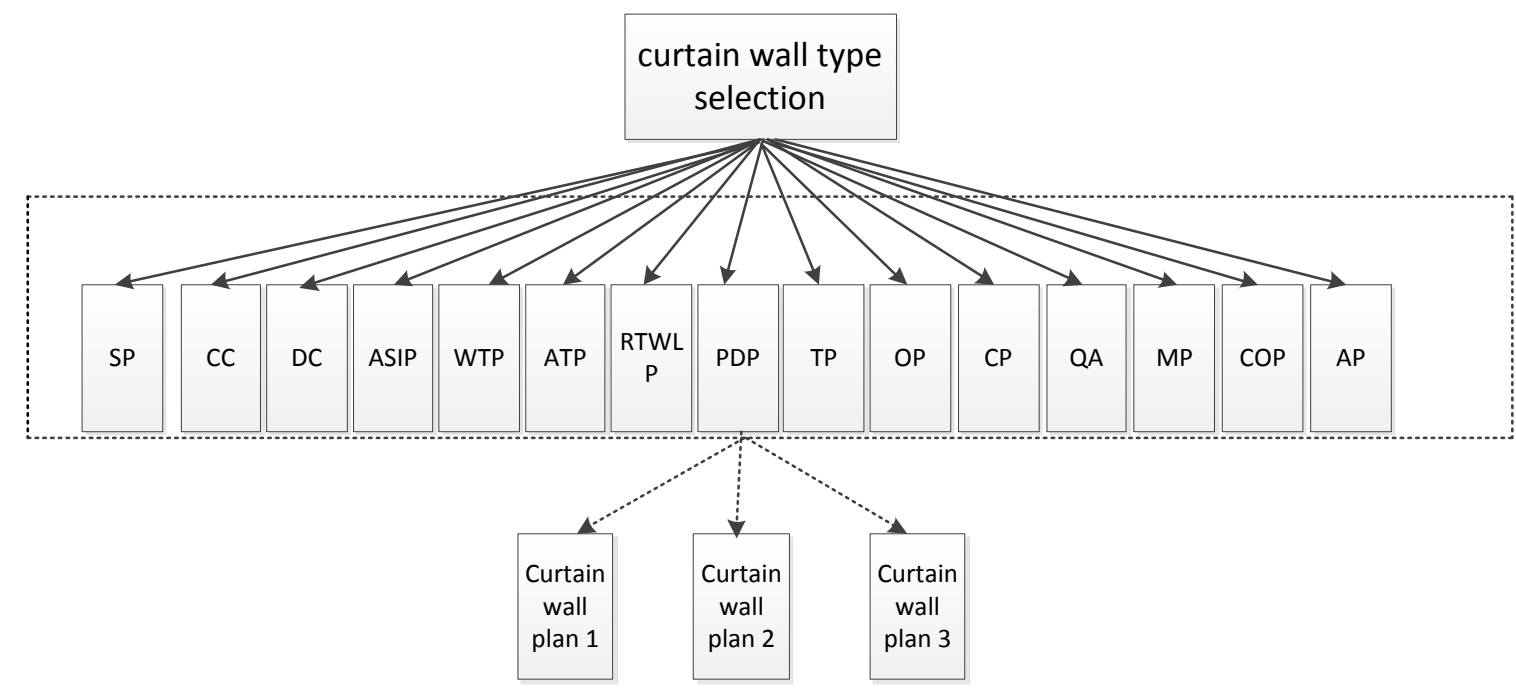

Figure 1. Hierarchical progressive mode

Table 1 Comparison matrix of criterion layer

\begin{tabular}{|c|c|c|c|c|c|}
\hline & Index1 & Index2 & Index3 & Index4 & $\cdots$ \\
\hline Index1 & & & & & \\
\hline Index2 & & & & & \\
\hline Index3 & & & & & \\
\hline Index4 & & & & & \\
\hline$\cdots$ & & & & & \\
\hline
\end{tabular}

Table 2 Comparison matrix of plan layer

\begin{tabular}{|c|c|c|c|c|}
\hline criterion & $\begin{array}{c}\text { Curtain wall } \\
\text { plan 1 }\end{array}$ & $\begin{array}{c}\text { Curtain wall } \\
\text { plan 2 }\end{array}$ & $\begin{array}{c}\text { Curtain wall } \\
\text { plan 3 }\end{array}$ & $\cdots$ \\
\hline Curtain wall plan 1 & & & & \\
\hline Curtain wall plan 2 & & & & \\
\hline Curtain wall plan 3 & & & & \\
\hline$\cdots$ & & & & \\
\hline
\end{tabular}

\section{Summary}

This paper selected impact indicators on the selection of curtain wall firstly and got different relative weight between the index weight by evaluating advantages of different curtain wall project on the different indicators. The weights show the relative merits of different curtain wall project, namely this paper construct a kind of curtain wall type selection decision-making model based on analytic hierarchy process.

\section{References}

[1] Lu Jinlong, Zuo Weiwen, Liu Xiong, Kou Yude. The development history and status of curtain wall at home and abroad [J]. Housing Science, 2009, 04: 46-49.

[2] National Standard of the People's Republic of China. Building curtain wall (GB/T21086-2007). Beijing: Standards Press of China, 2007

[3] Shanghai engineering construction standard. Technical code for building curtain wall engineering (DGJ08-56-2012). Beijing: China Architecture \& Building Pres, 2012 
[4] $\mathrm{Mu}$ Xiaoqiang. The contrast analysis between unit and frame curtain wall in engineering application [D]. Qingdao: Qingdao Technological University, 2014.

[5] Liu Hongtao,Liu Chuntao,Liu Xiangzhong. Simply introduction to the classification and characteristic of curtain wall structure [J]. Doors and Windows, 2010, 08: 6-15.

[6] Seung-Yeong Song, June-Seong Yi, Bo-Kyoung Koo. Insulation plan of aluminum curtain wall-fastening unit for high-rise residential complex [J]. Building and Environment, 2008, 43(7)

[7] Marine L, Perotti F. Numerical analysis of the nonlinear dynamic behavior of suspended cables under turbulent wind excitation [J]. International Journal of Structural Stability and Dynamics, 2006, 13(3): 207-233

[8] Chen Liansheng, Cha Enming, Jin Changjiang, Liu Xiangzhong. Introduction to building's typical curtain wall system method [J]. Doors and Windows, 2011(7): 16-19

[9] Satty. T. L. The Analytic Hierarchy Process [M]. New York: McGraw-Hill, 1980.

[10]A.M.Memai, A. Shirazi; P.A. Kremer. Static finite element analysis of architectural glass curtain walls under in-plane loads and corresponding full-scale test [J]. Structural Engineering and Mechanics, 2007, 25(4). 